\title{
O ATO DE NOMEAR NO DISCURSO DE ÓDIO CONTRA A MULHER
}

\author{
Ângela Alves de Araújo Barbosa ${ }^{1}$ \\ Richardson Silva ${ }^{2}$ \\ Denise Lima Gomes da Silva ${ }^{3}$
}

\begin{abstract}
RESUMO: $O$ ato de nomear é um processo marcado pela constituição de alteridade, em que o outro constitui nosso horizonte social (MOIRAND, 2004; SIBLOT, 1998, 2007). As palavras selecionadas para nomear o outro são carregadas de posicionamentos, apreciações e/ou ideologias. Ao referirmos o nosso outro pela nomeação, dizemos mais de nós mesmos, pois há uma tomada de posição por aquele que nomeia, uma definição de si, sendo este outro uma imagem ou objeto do discurso a ser referido. Considerando como o outro a mulher vitimizada pela violência pelo fato de ser mulher, objetivamos analisar a nomeação do corpo feminizado no contexto de violência doméstica e familiar contra a mulher até a culminância do feminicídio, cujas agressões são carregadas pelo discurso de ódio. Temos por questionamento, portanto: como a mulher é nomeada no discurso de ódio pelo autor da agressão, no contexto de violência doméstica e familiar contra a mulher, até a culminância do feminicídio? Nosso estudo está inserido na teoria dialógica da linguagem, com bases conceituais no dialogismo, no princípio da alteridade, no posicionamento, no ponto de vista e na apreciação dentro da concepção da nominação e do discurso de ódio, que impera no contexto violento, contra a resistência da vítima.
\end{abstract}

PALAVRAS-CHAVE: Nomeação. Dialogismo. Discurso de ódio. Violência contra a mulher. Corpo feminizado.

ABSTRACT: The act of naming is a process marked by the constitution of otherness, in which the other constitutes our social horizon (MOIRAND, 2004; SIBLOT, 1998, 2007). The words selected to name the other are loaded with positions, appraisals and / or ideologies. When referring to our other by nomination, we say more about ourselves, as there is a position taken by the nominator, a definition of himself and the other becomes an image or object of the discourse to be referred to. Considering like that other, the woman victimized by violence due to the fact of being a woman, we aim to analyze the nomination of the feminized body in the context of domestic and family violence against women until the culmination of feminicide, whose aggressions are carried over hate speech. Our question is, therefore, how is the woman named in the hate speech by the perpetrator of the aggression in the context of domestic and family violence against women until the climax of feminicide? Our study is inserted in the dialogical theory of language with conceptual bases in dialogism, in the principle of alterity, in the positioning, in the point of view and in the appreciation within the conception of the nomination and hate speech, which prevails in the context of violence, against the victim's resistance.

\footnotetext{
${ }^{1}$ Doutoranda filiada à Universidade Católica de Pernambuco (UNICAP-CAPES/PROSUC), no Programa de PósGraduação em Ciências da Linguagem, Recife, Pernambuco, Brasil. E-mails: aangelaraujo@gmail.com; angela.2019800009@unicap.br.

${ }^{2}$ Doutorando filiado à Universidade Católica de Pernambuco (UNICAP) pelo Programa de Pós-Graduação em Ciências da Linguagem e Professor Universitário filiado à Faculdade Boa Viagem DeVry Brasil (UniFBV | Wyden). Ambas as filiações em Recife, Pernambuco, Brasil. E-mail: richardson.sds@gmail.com.

3 Pós-doutora pela Universidade Católica de Pernambuco (UNICAP), no Programa de Pós-Graduação em Ciências da Linguagem, Recife, Pernambuco, Brasil. E-mail: dslima@gmail.com.
} 
PERcursos Linguísticos • Vitória (ES) •v. 10 •n. 25 • 2020 • ISSN: 2236-2592 • Dossiê:

Discursos de resistência e corpos (re)existentes •

KEYWORDS: Name. Dialogism. Hate speech. Violence against women. Feminized body.

\section{Introdução}

A Análise Dialógica do Discurso tem por marco os pesquisadores russos que vivenciaram o contexto da União Soviética de domínio stalinista e propuseram o dialogismo no âmbito da linguagem, dos discursos, com saturação ideológica e valorativa na dimensão da vida. Bakhtin, Volochínov e Medvedev são os nomes mais conhecidos do Círculo no ocidente.

O primeiro escrito filosófico de Bakhtin (1923/1993), Para uma filosofia do ato, constrói uma discussão acerca da relação alteritária, de espaço-tempo, que inter-relaciona a noção de organismo, posicionamento, excedente de visão, valoração, como também a concepção de ato e responsabilidade. O campo da experiência e o da vida são lugares desse desenvolvimento filosófico. Esta primeira fase filosófica de Bakhtin está presente no desenvolvimento dos demais trabalhos.

Volochínov (1929/2017) desenvolve as noções de signo ideológico, compreensão responsiva, enunciado concreto e diálogo, considerando seu interlocutor ou auditório social, no campo da linguagem, na sua obra amplamente conhecida Marxismo e Filosofia da Linguagem. Desenvolve o conceito de acento, acentuação ou apreciação em sua obra Discurso na vida e discurso na poesia.

Partindo da reflexão proposta pelos autores russos, Siblot (1990, 1997, 2001) e Moirand $(2009,2011)$ abordam o ato de nomear na perspectiva dialógica e axiológica. De acordo com esses autores, entre o sujeito e a realidade nomeada existe uma multiplicidade de interações, de representações e de sentidos que é reajustada a cada atualização discursiva. As palavras são revestidas de uma memória, e cada ato enunciativo, que é singular, revela um ponto de vista do enunciador.

Portanto, com base na perspectiva dialógica do discurso proposta pelos autores russos, e na leitura sobre o ato de nomear proposta por Siblot e Moirand, propomos, neste artigo, refletir sobre o discurso violento, mais precisamente no contexto de violência doméstica e familiar contra a mulher, a partir das agressões verbais do enunciador e seus desdobramentos. Para tanto, as nomeações proferidas pelo enunciador serão a unidade de análise que condensa posicionamentos, apreciações e ideologias, com marcação da relação de alteridade: relacionamento violento, verbalização violenta contra a mulher, disseminação do discurso de ódio.

Para a seleção do corpus, realizamos uma leitura prévia de casos de violências contra a mulher no contexto doméstico e familiar, de domínio público, divulgados pela mídia 
PERcursos Linguísticos • Vitória (ES) •v. 10 •n. 25 • 2020 • ISSN: 2236-2592 • Dossiê:

Discursos de resistência e corpos (re)existentes •

jornalística na rede de computadores (internet). O corpus selecionado foi originário do caso de feminicídio em massa conhecido como "a chacina em Campinas", que causou grande impacto no Brasil, divulgado pelo jornal Estadão, com o título de "Autor de chacina em Campinas escreveu carta sobre seu plano" (ESTADÃO, 2017). ${ }^{4}$ Trechos da carta foram publicados no jornal, apresentando conteúdo misógino, verbalização de discurso de ódio por parte do agressor que culminou em feminicídio.

\section{Linguagem e dialogismo}

Nas críticas de Volochínov aos formalistas russos, no início do século XX, quando trata dos "problemas fundamentais do método sociológico na ciência da linguagem", o objetivismo abstrato e o subjetivismo idealista são combatidos por ele. $\mathrm{O}$ autor russo defende uma concepção de linguagem indissociável das condições de comunicação e das estruturas sociais, colocando a criação ideológica no domínio dos signos: "Sem signo, não existe ideologia. [...] Todo signo está sujeito aos critérios de avaliação ideológica [...] Ali onde um signo se encontra, encontra-se também a ideologia. Tudo que é ideologia possui um valor semiótico" (VOLOCHÍNOV, 1929/2017, p. 31-32).

Sériot (2015) esclarece a definição de ideologia em Volochínov, que é diferente das definições de outras análises do discurso sobre alienação do sujeito. Essa definição da ideologia é, portanto, "[...] o conjunto dos produtos culturais dos quais faz parte a ciência: são todas as ideias que as pessoas têm na cabeça, conjunto sempre manifesto e transparente na consciência [...]" (SÉRIOT, 2015, p. 16). O autor também mostra uma definição de ideologia compreendida e assumida por Volochínov, que frisa ter sido a única ocasião em que ele a definiu, em Marxismo e Filosofia da Linguagem (MFL), como todo conjunto do que é refletido e refratado da realidade social e natural pela consciência e que seja expressada e fixada por ela sob qualquer forma semiótica, incluindo a forma verbal (SÉRIOT, 2015).

Dessa maneira, a palavra é o "fenômeno ideológico par excellence" (VOLOCHÍNOV, 1929/2017, p. 98). A palavra-discurso é definida como um campo de batalha e denominada de arena, onde valores sociais divergentes entram em confronto, em uma cadeia dialógica, em movimento constante. A palavra-signo é um palco de luta de classes, em que há o cruzamento de interesses sociais com ênfases multidirecionadas, que Volochínov (1929/2017) denomina de multiacentuação do signo ideológico, cujo cruzamento de acentos dá vida, movimenta e desenvolve o signo.

\footnotetext{
${ }^{4}$ ESTADÃO. Conteúdo 01/01/17 - 18h33 - Atualizado em 01/01/17 - 19h29.
} 
Bakhtin (2016) também irá defender que toda comunicação é sempre dialógica, constituída pela lógica da interação semiótica. As relações dialógicas são relações semânticoaxiológicas entre todas as espécies de enunciados na comunicação discursiva. O discurso é, em Bakhtin (2016), a língua in actu, sendo inadmissível contrapor língua e discurso. O discurso é tão social quanto a língua, e as formas de enunciado, assim como a língua, são sociais e igualmente determinadas pela comunicação.

Conforme Todorov (1981), o dialogismo enquanto essência da linguagem está ligado à concepção de mundo como acontecimento; da realidade, enquanto processo; e do ser, em constante devir pela palavra. Entre o discurso e o objeto, diz Bakhtin (2015, p. 48), existe um meio "elástico e amiúde dificilmente penetrável de outros discursos alheios a respeito do mesmo objeto, no mesmo tema". É somente no processo de interação viva e tensa, uma vez que não há sujeito passivo, que o sujeito concorda, discorda, reage e age com o discurso que se individualiza.

É justamente nesta dialética axiológica entre linguagem e realidade que veremos a questão da nominação a seguir.

\section{$O$ ato de nomear: dialogismo da nominação}

O ato de nomear ${ }^{5}$ (MOIRAND, 2004; SIBLOT, 1998, 2007) é um processo marcado pela constituição de alteridade, em que o outro constitui nosso horizonte social. Advém do dialogismo da nominação, de estudos franceses do campo da Praxemática. As palavras selecionadas para nomear o outro são carregadas de posicionamentos, apreciações e/ou ideologias. Ao referirmos o nosso outro pela nomeação, dizemos mais de nós mesmos, pois há uma tomada de posição por aquele que nomeia, uma definição de si, sendo este outro uma imagem ou objeto do discurso a ser referido.

De acordo com Siblot (2001), dialética entre locutor e realidade nomeada abarca uma multiplicidade de interações, categorizações, representações e sentidos que são reajustados a cada atualização discursiva. Nomear é não apenas se situar em relação ao objeto, mas também tomar uma posição em relação a outras denominações do mesmo objeto. Dessa maneira, uma reflexão sobre a questão da nomeação envolve uma dialética entre linguagem e realidade. $\mathrm{O}$ objeto é nomeado a partir de um ponto de vista, do lugar que o enunciador ocupa e o percebe,

\footnotetext{
${ }^{5} \mathrm{O}$ ato de nomear tem por sinônimo o ato de nominar. As traduções são a partir do francês, podendo encontrar também os termos nominação ou nomeação como sinônimos. Optamos em deixar no título do artigo a tradução designada em nominação e no corpo do texto optamos por nomeação, enfatizando que são sinônimos no Dialogismo da nominação/nomeação.
} 
tomando uma posição diante do objeto e da diversidade de nomeações relacionada a ele.

Para Moirand (2011, p. 170-171), três dimensões estão relacionadas ao ato de nomear:

A realidade do mundo, que categorizamos para lhe dar significado; a realidade do sujeito, que expressa a representação que ele faz deste mundo e a posição que ele toma em relação a ele; a realidade do sujeito para outras pessoas com quem ele necessariamente entra em diálogo. (grifos nossos).

De acordo com Cordeiro (2017), o estudo do dialogismo da nominação está interrelacionado às vozes sociais, pois:

[...] as palavras são trazidas e retomadas por meio de numerosas vozes. Algumas delas, inclusive, tentam "aprisionar" os sentidos em que certas palavras são usadas. Contudo as palavras não tratam de um objeto que é mudo, mas circulam na vida e são empregadas pelos sujeitos em planos axiológicos distintos e por meio de pontos de vista, desejos e afetos que também podem ser diversos. (CORDEIRO, 2017, p. 59).

O ato de nomear na relação de alteridade (eu para o outro, o outro para mim, eu para mim mesmo) implica, pois, relações de sentidos e valorações que, no contexto de violência doméstica e familiar contra a mulher, a relação alteritária é de dominação e submissão, mobilizando a nomeação de saturação ideológica/axiológica sobre a mulher, sobre seu corpo feminizado.

\section{Discurso do ódio e violência}

O discurso de ódio tem íntima relação com a violência contra o outro. Nas palavras de Garcia et al. (2008, p. 2551), "a violência contra o ser humano é um dos eventos bioéticos de maior relevância, pois, além dos danos físicos e psicológicos que ocasiona, necessita de um grande número de ações para a sua prevenção e tratamento".

Especificamente no que concerne ao discurso de ódio, Schäfer, Leivas e Santos (2015, p. 147) demarcam traços característicos e tipos desse discurso, partindo do direcionamento discursivo, pois este é orientado para "estigmatizar, escolher e marcar um inimigo, manter ou alterar um estado de coisas, baseando-se numa segregação. Para isso, entoa uma fala articulada, sedutora para um determinado grupo, que articula meios de opressão”.

Dois tipos distintos de discurso de ódio, do ponto de vista conceitual, são verificados por Rosenfeld (2001 apud SCHÄFER; LEIVAS; SANTOS, 2015). Estes tipos são denominados de hate speech in form, manifestando explicitamente o ódio, e hate speech in substance ou discurso de ódio velado, que "pode apresentar-se disfarçado por argumentos de proteção moral e social, [...] pode provocar agressões a grupos não dominantes. Ele produz violência moral, preconceito, discriminação e ódio contra grupos vulneráveis e intenciona articuladamente a sua segregação" (ROSENFELD, 2001 apud SCHÄFER; LEIVAS; SANTOS, 2015, p. 147). 
O discurso de ódio contra a mulher, de conteúdo misógino, é configurado como crime no Brasil por propagar ódio ou aversão às mulheres, de acordo com a Lei n. 13.642, de 3 de abril de 2018, sendo assim um atentado aos direitos humanos de ação discriminatória e de intolerância que incita a violência. É um discurso que tende à hierarquização, à anulação da pluralidade humana.

O discurso de ódio também é compreendido, em seu sentido amplo, como violência verbal por sua base discursiva de rejeição do convívio com as diferenças, motivado por preconceitos sociais. Por vezes, também é denominado de agressão verbal. Cunha (2013) explica que, nos estudos linguísticos, a violência verbal é uma noção geral para verbalizações de insultos, ataques pessoais, xingamentos, palavrões, etc.; e alguns desses termos são utilizados como sinônimos pela fluidez das noções. No contexto de violência doméstica e familiar contra a mulher à culminância do feminicídio (crime de ódio), as agressões verbais são recorrentes, tornando-se gradativamente mais violentas em discursos que minam ódio, em um ciclo de violências diversas.

Estudos sobre a temática da violência doméstica e familiar contra a mulher e sobre o feminicídio apontam que o agressor assume uma posição de possuidor da vítima, cuja representação para o agressor é de objeto de posse, estando o corpo feminizado percebido e estabelecido nessa relação como objeto.

\section{O corpo feminizado: violência doméstica e familiar contra a mulher}

Federici (2017 apud ASSIS; ALVES, 2017) atribui ao corpo da mulher "a última fronteira de conquista do capital" e que "a dependência econômica é a última forma de controle sobre nossa sexualidade" (FEDERICI, 2019, p. 59), indicando o ódio da mulher sobre o próprio corpo, referindo-se à comercialização do corpo feminino, porque:

Precisamente por causa da troca envolvida, a sexualidade para nós é sempre acompanhada por ansiedade, e essa é sem dúvida a parte do trabalho doméstico mais responsável pelo ódio que sentimos de nós mesmas. Além disso, a comercialização do corpo feminino torna impossível que nos sintamos confortáveis com o nosso corpo, independentemente de suas medidas ou formas. (FEDERICI, 2019, p. 59).

Segundo Federici (2019), a respeito do ódio do homem contra a mulher, no contexto doméstico e familiar, "os homens têm sido sempre autorizados a voltar seu ódio contra nós se não estivermos à altura do papel, particularmente quando nos recusamos a executá-lo" (p. 57). Assim:

[...]inevitavelmente nos tornamos o objeto sobre o qual os homens descarregam sua violência reprimida. Somos estupradas, tanto em nossa cama quanto na rua, precisamente porque fomos configuradas para ser as provedoras da satisfação sexual, as válvulas de escape para tudo o que dá errado na vida dos homens. (FEDERICI, 2019, p. 57, grifo nosso). 
PERcursos Linguísticos • Vitória (ES) •v. 10 •n. 25 • 2020 • ISSN: 2236-2592 • Dossiê:

Discursos de resistência e corpos (re)existentes •

Ainda segundo afirmação da autora, questionar sobre o que é ser "mulher" significa implorar por uma resposta sexista.

O feminicídio, portanto, é o último estágio de agressão, a violência extrema, um crime de ódio motivado pela razão de a vítima ser mulher. Reflete uma estrutura de superioridade do agressor para com a vítima, uma ação autoritária, rompendo o princípio da relação de alteridade com a inexistência de diálogo no sentido bakhtiniano. Dito isso, "o não reconhecimento do outro é a morte" (FARACO, 2019).

\section{Análise do corpus}

Para iniciarmos a análise, traremos a contextualização do crime a partir da matéria publicada, intitulada de "Autor de chacina em Campinas escreveu carta sobre seu plano”, com conteúdo de responsabilidade do Estadão, em 01/01/17. O autor do crime deixou cartas premeditando matar a ex-mulher, o filho e membros da família, executando tiros no momento de celebração de Réveillon. ${ }^{6}$ Mediante trechos de uma das cartas escritas pelo agressor/executor do crime, publicada em domínio público, segue a análise do ato de nomear na violência verbal contra a mulher.

De início, a carta foi direcionada ao próprio filho, que também foi vítima do assassinato, justificando para o menor sua motivação do crime, um feminicídio em massa, seguido de suicídio. No decorrer da carta, o autor faz referência à ex-mulher com discurso de ódio, de conteúdo misógino, culpando não apenas a ex-mulher, mas todas as mulheres, como apresentado neste enunciado:

(i) por causa de um sistema feminista e umas loucas.

A verbalização de ódio do agressor está explicitamente direcionada ao gênero [discriminação de gênero], ao movimento feminista, instaurando uma oposição ideológica. Ao nomear todo corpo feminino como um sistema feminista, marca sua posição de menosprezo sobre o sistema e reflete sua autoridade na fala, indiciando a representação "das outras" [ $e$ umas loucas] no somatório do sistema feminista. A relação do agressor com o outro aponta duas formas relacionais, uma de ordem social/ideológica/cultural e outra de ordem subjetiva/emocional, mobilizando uma antecipação do ato agressivo de nomear a ex-mulher e as mulheres que compõem a família da vítima [loucas]. O agressor segue o direcionamento da violência verbal contra a ex-mulher, no enunciado abaixo, denotando o corpo feminizado, em

\footnotetext{
${ }^{6}$ Disponível em: https://istoe.com.br/autor-de-chacina-em-campinas-escreveu-carta-sobre-seu-plano/333/. Acesso em: 16 mar. 2020.
} 
verbalização odiosa de xingamento, na qualificação de vadia.

(ii) A vadia foi ardilosa e inspirou outras vadias a fazer o mesmo com os filhos, agora os pais quem irão se inspirar e acabar com as famílias das vadias. As mulheres sim têm medo de morrer com pouca idade.

O tom negativo da nomeação cria uma imagem do outro em padrões amorais, com conotações de ordem sexual e de estereótipo feminino. Esse ato de nomear reflete, no próprio agressor, um padrão machista, sexista. Além de vadia, o seu discurso qualifica a vítima de ardilosa, fonte de inspiração maléfica, provocadora da mesma "ação maléfica" em outras mulheres consideradas por ele como vadias. Esse ato do agressor fala mais de si mesmo por ser o reflexo de sua própria intenção, por desejar ser ele mesmo a fonte de inspiração para outros homens, refratando uma soberania da qualidade masculina sobre a qualidade feminina. Impõe-se como a fonte de inspiração não maléfica, uma inspiração de justiça. Seu discurso tem uma articulação explícita de ódio, destila ódio, incita a violência contra mulheres, mas, ao mesmo tempo, procura velar o discurso através de uma justificativa de reversão discursiva, culpabilizando e desqualificando o corpo feminizado pelas nomeações de vadias, loucas, feministas, medrosas. Sua articulação discursiva instiga um desdobramento de ódio para a conjuntura familiar de outras famílias, incita a mesma prática a outros homens. Nesse sentido, os enunciados (i) e (ii) podem ser compreendidos na perspectiva de Siblot (2001), quando este afirma que a dialética entre enunciador e realidade nomeada abarca uma multiplicidade de interações, categorizações, representações que são reajustadas a cada atualização discursiva. É possível perceber, então, que o discurso violento, nos enunciados (i) e (ii), é constituído por mecanismos de sentidos, cujas nomeações - vadias, loucas, feministas, medrosas, ardilosa são recuperadas da memória histórico-cultural e patriarcal, e seu caráter axiológico depreciativo é ratificado.

No enunciado seguinte, o agressor encadeia sua verbalização odiosa com a nomeação de bandidas, dimensionando para a corrupção do país, minimizando e ridicularizando-o por paizeco, assim como para as leis vigentes. Retoma a nomeação de vadias correlacionando ao não merecimento e às atitudes erradas de todas as mulheres/vadias como causadoras do distanciamento entre os filhos e seus genitores [homens], apoiadas pela lei. Do ponto de vista do agressor, ele reflete uma avaliação de si mesmo como vítima, injustiçado e de ações corretas. A lei e as mulheres [mães] são suas inimigas.

(iii) Ela não merece ser chamada de mãe, mas infelizmente muitas vadias fazem de tudo que é errado para distanciar os filhos dos pais e elas conseguem, pois as leis deste paizeco são para os bandidos e bandidas.

A carta do agressor direcionada ao filho antecipa a resposta com uma articulação verbal do tipo discurso de ódio velado, com um disfarce argumentativo de "proteção moral e social", 
para convencer o filho. No enunciado (iv), o uso de negação (não sou machista e não tenho raiva das mulheres) encadeado pela afirmação constitui uma contraposição valorativa, carrega determinações axiológicas. De acordo com Bakhtin (2011), ao elaborar seu ponto de vista, o enunciador dialoga com o discurso do outro em diferentes graus de alteridade, seja em relação de maior ou menor convergência ou divergência. Dessa forma, a negação (iv) aponta a presença do dialogismo interdiscursivo, a existência de duas vozes dialógicas divergentes, indicando ser o objeto da negação, uma afirmação.

O corpo feminizado novamente é nomeado como objeto amoral, com fins reprodutivos para receber benefícios por isso. A lei de proteção às mulheres vítimas de violência doméstica e familiar, a Lei Maria da Penha, recebe a nomeação de vadia. O agressor retoma as referências das nomeações anteriores, da bandidagem assegurada pela lei e de um sistema feminista corrompido, que frustra sua autorrepresentação masculina. A Lei Maria da Penha é alvo da agressão verbal, em que o agressor expressa sua raiva contra a resistência feminina e os direitos assegurados pelas mulheres com a proteção da lei.

(iv) Filho, não sou machista e não tenho raiva das mulheres (essas de boa índole, eu amo de coração, tanto é que me apaixonei por uma mulher maravilhosa, a Kátia), tenho raiva das vadias que se proliferam e muito a cada dia se beneficiando da lei vadia da penha!

A mulher nomeada como inimiga é a raiz do mal, cuja vulnerabilidade feminina está no medo da morte. No enunciado abaixo, o agressor revela seu propósito de matar a ex-esposa como um ato vingativo. Sua entonação expressa um lugar que ele ocupa como homem detentor do direito de executar seu crime de ódio contra a(s) vítima(s), o feminicídio, o não reconhecimento do outro. Profere seu discurso autoritário como um ato de castigo merecido pela vítima e sua família, deixando como exemplo para que outros homens também venham a executá-lo. Demonstra, dessa forma, sua "virilidade", "superioridade" - uma demonstração de força contra a resistência do corpo feminizado. Quando verbaliza que "a força está em suas mãos", a decisão de matar sua vítima reflete o quanto a resistência feminina o incomoda, não aceitando o empoderamento feminino. Há, portanto, um embate em seu próprio discurso.

(v) [...] vou vingar o mal que ela nos fez! [...] Toda mulher tem medo de morrer nova, ela irá por minhas mãos!

A nomeação vadia é o eixo-valorativo da violência verbal do agressor para minimizar a mulher e as demais, destruindo o corpo feminizado para construir uma imagem superior de si. Ser forte e homem é verbalizar o ódio que se estende à violência física.

(vi) Sei que me achava um frouxo em não dar uns tapas na cara dela, mas eu não podia te dizer as minhas pretensões em acabar com ela! Tinha que ser no momento certo. Quero pegar o máximo de vadias da família juntas.

(vii) Chega!! Ela tem que pagar pelo que fez. 
PERcursos Linguísticos • Vitória (ES) •v. 10 •n. 25 • 2020 • ISSN: 2236-2592 • Dossiê:

Discursos de resistência e corpos (re)existentes •

O corpo feminizado é requerido pelo agressor. O grito autoritário exige o preço pelo corpo feminizado que ainda resiste.

\section{Considerações finais}

$\mathrm{O}$ ato de nomear no discurso de ódio, no corpus analisado, revelou um embate discursivo para ferir e destruir o outro em duas modalidades de discurso de ódio - explícito e velado. $\mathrm{O}$ ato de nomear a vítima pelo agressor demonstrou a saturação ideológica machista/sexista, o posicionamento violento e a apreciação de ódio, repugnância e desprezo.

O corpo feminizado foi nomeado como objeto amoral para fins reprodutivos, desdobrado pelas nomeações vadias, ardilosas, bandidas, mulher medrosa, loucas. Procurando criar uma imagem negativa desse outro, o encadeamento dos enunciados do agressor reflete sua própria imagem, ou seja, no ato de nomear a mulher de maneira que a minimiza para exaltar a si mesmo, o funcionamento do seu discursivo torna-se reverso, revelando o corpo feminizado em resistência.

O próprio discurso de ódio do agressor revela um embate de corpos, que ele amplia para o movimento feminista, para a instituição da família (mulheres, esposas, mães), para a Lei Maria da Penha, impondo seu discurso autoritário, que rompe o dialogismo.

\section{Referências}

ASSIS, C.; ALVES, L. 'O corpo da mulher é a última fronteira de conquista do capital', diz historiadora italiana Silvia Federici. Opera Mundi. São Paulo, 24 de dezembro de 2017. Disponível em: https://operamundi.uol.com.br/politica-e-economia/48536/corpo-da-mulher-eultima-fronteira-de-conquista-do-capital-diz-historiadora-italiana-silvia-federici. Acesso em: 28 abr. 2020.

BAKHTIN, M. M. Para uma filosofia do ato. Tradução de Carlos Alberto Faraco e Cristovão Tezza da edição americana Toward a philosophy of the act. Austin: University of Texas Press, 1993. (Tradução destinada exclusivamente para uso didático e acadêmico).

BAKHTIN, M. M. Teoria do romance I. A estilística. São Paulo: Editora 34, 2015.

BAKHTIN, M. M. Os gêneros do discurso. São Paulo: Editora 34. 2016.

CHÄFER, G.; LEIVAS, P. G. C.; SANTOS, R. H. Discurso de ódio: da abordagem conceitual ao discurso parlamentar. Revista de Informação Legislativa, Brasília, ano 52, n. 207, p. 143158, jul./set. 2015. Disponível em: https://www12.senado.leg.br/ril/edicoes/52/207/ril_v52_n207_p143. Acesso em: 15 abr. 2017. 
CORDEIRO, R. Q. F. Nominações, vozes e pontos de vista sobre a loucura na e pela mídia: da reforma psiquiátrica ao boom das doenças mentais. Recife, 2017. 477 f.: il., fig. Tese (Doutorado em Letras) - Programa de Pós-Graduação em Letras, Universidade Federal de Pernambuco, $\quad$ Recife, 2017. Disponível em: https://repositorio.ufpe.br/handle/123456789/24983. Acesso em: 29 maio 2020.

CUNHA, D. A. C. Violência verbal nos comentários de leitores publicados em sites de notícia. Calidoscópio, São Leopoldo: Usinos, v. 1, n. 3, p. 24-249, set./dez. 2013. https://doi.org/10.4013/cld.2013.113.02. Disponível em: http://revistas.unisinos.br/index.php/calidoscopio/article/view/cld.2013.113.02. Acesso em: 11 maio 2020.

FARACO, C. A. Seminário Bakhtin, autoria, axiologia e heteroglossia. Universidade Católica de Pernambuco, 2019.

FREDERICI, S. O ponto zero da revolução: trabalho doméstico, reprodução e luta feminista. São Paulo: Editora Elefante, 2019.

GARCIA, M. V. et al. Caracterização dos casos de violência contra a mulher atendidos em três serviços na cidade de Uberlândia, Minas Gerais, Brasil. Cad. Saúde Pública, Rio de Janeiro, v. 24, n. 11, p. 2551-2563, nov. 2008. https://doi.org/10.1590/S0102-311X2008001100010. Disponível em http://www.scielo.br/scielo.php?script=sci_arttext\&pid=S0102311X2008001100010\&lng=en\&nrm=iso. Acesso em: 29 maio 2020.

MOIRAND, S. De la nomination au dialogisme: quelques questionements autour de l'objet de discours e de la mémoire des mots. In: CASSANAS, A.; DEMANGE, A.; LAURENT, B.; LECLERC, A. Dialogisme et nomination. Montpellier, Publications de l'Université de Montpellier 3, 2004, p. 27-61.

MOIRAND, S. Du sens tel qu'il s'inscrit dans l'acte de nommer. 2011. Disponível em: https://hal-univ-paris3.archives-ouvertes.fr/hal-01503526/document. Acesso em:

SÉRIOT, P. Vološinov e a filosofia da linguagem. São Paulo: Parábola Editorial, 2015.

SIBLOT, P. Une linguistique qui n'a plus peur du réel. Cahiers de praxématique 15. Montpellier: Pulm. 57-76. 1990.

SIBLOT, P. Nomination et production de sens: le praxème. Langages Année, 1997, v. 31. n. 127. p. 38-55.

SIBLOT, P. De l'un à l'autre. Dialectique et dialogisme de la nomination identitaire. In: BRÈS, J.; DELAMOTTE-LEGRAND, R.; MADRAY-LESIGNE, F.; SIBLOT, P. (eds.). L'Autre en discours. Montpellier: Publications de l'Université Paul Valéry, Montpellier 3, 1998, p. 27-43.

SIBLOT, P. De la dénomination à la nomination. Les dynamiques de la signifiance nominale et le propre du nom. Cahiers de praxématique, v. 36, p. 189-214, 2001. 
PERcursos Linguísticos • Vitória (ES) •v. 10 •n. 25 • 2020 • ISSN: 2236-2592 • Dossiê:

Discursos de resistência e corpos (re)existentes •

SIBLOT, P. Nomination et point de vue: La composante déictique des catégorisations lexicales. In: CISLARU, G. L'acte de nomme: Une dynamique entre langue et discours. Paris: Presses Sorbonne Nouvelle, 2007, p. 25-38.

TODOROV, T. Mikhaïl Bakhtine. Le Principe Dialogique. Paris: Éditions du Seuil, 1981.

VOLOCHÍNOV, V. Marxismo e filosofia da linguagem: problemas fundamentais do método sociológico na ciência da linguagem. Tradução, notas e glossário de Sheila Grillo e Ekaterina Vólkova Américo; ensaio introdutório de Sheila Grillo. São Paulo: Editora 34, 2017. 376p. 